\title{
Non-noble metal single-atom catalysts with phosphotungstic acid (PTA) support: A theoretical study of ethylene epoxidation
}

\author{
Shamraiz Hussain Talib ${ }^{1}$ Xiaohu Yu ${ }^{2^{*}}$, Qi Yu ${ }^{3}$, Sambath Baskaran ${ }^{4}$ and Jun $\mathrm{Li}^{1,4^{*}}$
}

\begin{abstract}
Geometric and electronic structures of phosphotungstic acid (PTA) supported single transition metal atom $(\mathrm{Fe}, \mathrm{Co}, \mathrm{Ni}, \mathrm{Ru}, \mathrm{Rh}, \mathrm{Pd}, \mathrm{Os}$, Ir and $\mathrm{Pt}$ ) catalysts have been systematically investigated by using the first-principles theoretical methods. Possible reaction mechanism for ethylene epoxidation was explored. The most possible anchoring site for the single transition metal atom is the fourfold hollow site on PTA. As the non-noble metal $\mathrm{Fe}_{1}$-PTA system possesses considerable adsorption energies towards both $\mathrm{O}_{2}$ and $\mathrm{C}_{2} \mathrm{H}_{4}$, the strong bonding interaction between $\mathrm{Fe}_{1}$ and PTA cluster was analyzed. It is found that the electron transfers from $\mathrm{Fe}$ atom to PTA cluster and strong covalent metal-support interactions (CMSI) between the Fe $3 \mathrm{~d}$ orbitals and $\mathrm{O} 2 \mathrm{p}$ orbitals of PTA lay the foundation of high stability. The proposed catalytic reaction mechanism for ethylene epoxidation on $\mathrm{Fe}_{\mathbf{1}^{-}}$ PTA single-atom catalyst (SAC) includes three steps: the $\mathrm{O}_{2}$ adsorbs on $\mathrm{Fe}_{1}$-PTA via electron transfer; the first ethylene attacks the adsorbed $\mathrm{O}_{2}$ molecule on $\mathrm{Fe}_{1}$-PTA followed by the formation of $\mathrm{C}_{2} \mathrm{H}_{4} \mathrm{O}$; finally, the $\mathrm{O}$ atom remained on $\mathrm{Fe}_{1}$-PTA reacts with a second ethylene to form the product and accomplish the catalytic cycle. The $\mathrm{Fe}_{1}$-PTA has high selectivity and catalytic activity for ethylene epoxidation via an EleyRideal mechanism with low energy barriers. A potentially competitive pathway for the formation of acetaldehyde is not kinetically favorable. These results provide insights for the development of highly efficient heterogeneous SACs for ethylene epoxidation with non-noble metals.
\end{abstract}

Keywords: single-atom catalyst, non-noble metal, phosphotungstic acid, ethylene epoxidation, computational modeling

\section{INTRODUCTION}

Single atom catalysts (SACs) have aroused significant interest both experimentally and theoretically in heterogeneous catalysis since Qiao et al. [1] reported for the first time that the isolated Pt single atom supported by iron oxide showed excellent catalytic performance for $\mathrm{CO}$ oxidation. A number of experimental and computational studies show that SACs are promising for precise control of catalytic reactions due to the well-defined active sites and for potential industrial applications because of their high catalytic activity, stability, efficiency and selectivity [2-4]. SACs have been prepared by dispersing transition metal atoms on the surface of support, where single metal atoms surrounded by other atoms from the support serve as the active sites to provide unique chemical and physical properties [5-12]. Especially, the metal atom utilization efficiency is greatly increased by the atom form disperse, which helps to reduce the demand and costs of noble metals often used in industrial catalysis. Due to the versatility and tunability of the coordination environment at the single-atom metals, SACs also provide peculiar opportunity for developing catalysts with non-noble metal atoms at the active center [13-16].

Compared with the nanoparticle-based catalysts or metal clusters, the active sites of SACs have different electronic and geometrical structures; particularly the varied oxidation states, charges, and valence shell electronic configurations of the metal atoms render special physicochemical properties and outstanding catalytic

\footnotetext{
${ }^{1}$ Department of Chemistry and Key Laboratory of Organic Optoelectronics \& Molecular Engineering of Ministry of Education, Tsinghua University, Beijing 100084, China

${ }^{2}$ Shaanxi Key Laboratory of Catalysis and School of Chemical \& Environment Sciences, Shaanxi University of Technology, Hanzhong 723000, China

${ }^{3}$ School of Materials Science and Engineering and Institute of Graphene at Shaanxi Key Laboratory of Catalysis, Shaanxi University of Technology, Hanzhong 723001, China

${ }^{4}$ Department of Chemistry, Southern University of Science and Technology, Shenzhen 518055, China

* Corresponding Authors (emals: yuxiaohu@snut.edu.cn (Yu X); junli@tsinghua.edu.cn (Li J))
} 
performance. One of the challenges of practical application of SACs is the intrinsic static stability and the dynamic stability under reaction conditions of the catalysts. Because of the high surface free energy of low-coordinated metal atoms, these atoms tend to aggregate into small clusters or nanoparticles on support, especially under high-temperature and redox reactions. Therefore, a significant effort has been devoted to the field of SACs for developing suitable supports that can effectively anchor the single metal atom on the supports, without reducing the performance of the catalyst and devastating supports [17-20]. Currently, a series of practically utilized supports are studied for SACs, including reducible and irreducible oxides, nitrides, carbides, metals, as well as carbon or carbon-nitrogen materials [21-25].

In the field of catalytic reactions with nanoparticles, direct epoxidation of ethylene to ethylene oxide $\left(\mathrm{C}_{2} \mathrm{H}_{4} \mathrm{O}\right)$ catalyzed by $\mathrm{Ag}$ is a vital chemical process because ethylene oxide is an important raw material for the production of useful chemical products such as glycols, plastics, polyester, and other fine chemicals [26-28]. Experimentally, the selectivity of ethylene oxide over clean $\mathrm{Ag}$ is about $40 \%-50 \%$, and its selectivity can be increased to $90 \%$ by the accumulation of solid promoters such as alkali metals as well as Re and Mo [27-29]. Among numerous experimental studies, van Hoof et al. [30] studied the ethylene epoxidation over Ag catalysts by adding selective species, and found that substantial impact of a small amount of impurity on a well-studied heterogeneous catalyzed reaction. These results point to the importance of adding fine-selected "impurity" on improving catalytic reaction performance for ethylene epoxidation.

Among the various metal oxide supports, polyoxometalate (POM) clusters are heteropolyacid oxoanions that posses considerable stability, well-defined structures, and interesting catalytic properies, thus being a promising support for developing SACs with high stability. The solid POMs possess a separate anionic structure, which is more like a distinct portion of the solid metal oxides [30-41]. For many years, POMs have been used as catalyst support materials due to the following advantages. (i) POMs are an isolated and compact anionic structure. The reported cluster compounds have been characterized by X-ray single crystal diffraction. (ii) POMs have a discrete anionic structure due to the dissolution of both organic solvent and water and can act as heterogeneous as well as homogeneous catalysts. (iii) Due to the isolated and robust structure of POMs both in solution and solid phase, it can be easily examined by using chemical and spectroscopic technologies [42-47]. (iv) A number of theoretical studies on the bonding, stability, and physicochemical properties have also been done for various POMs [48-50]. Thus, POMs are ideal system which provides an opportunity to study the mechanistic behavior of SACs at molecular levels.

In the POMs family, of particular importance are the Keggin type structures of phosphomolybdic acid $\left(\mathrm{H}_{3} \mathrm{PMo}_{12} \mathrm{O}_{40}\right.$, PMA) and phosphotungstic acid $\left(\mathrm{H}_{3} \mathrm{PW}_{12} \mathrm{O}_{40}, \mathrm{PTA}\right)$, which consist of tungsten or molybdenum and oxygen atoms with a $\mathrm{PO}_{4}$ unit located at the center of $\mathrm{M}_{12} \mathrm{O}_{36}$ cage. These POMs have attracted remarkable attention recently in SACs, owing to the unusual properties in catalysis and energy storage. $\mathrm{He}$ et al. [51] reported the first SAC of palladium substituted Wells-Dawson polyoxometalate (Pd-POM) which showed high catalytic activity for Suzuki-Miyaura coupling and semihydrogenation reactions. Yan and colleagues $[52,53]$ found remarkable performance of SACs with PMA and PTA structures. They deposited Rh on the PTA surface via a self-assembly method and found that $\mathrm{Rh}$ catalyst exhibited excellent stability in the reaction of $\mathrm{CO}$ oxidation when the loading of $\mathrm{Rh}$ was reduced to $0.9 \mathrm{wt} \%$. They also reported that the Pt single atom supported by PMA did not compromise hydrogen activity and the loading of $1 \mathrm{wt} \% \mathrm{Pt}$ showed excellent catalytic performance in the hydrogenation of nitrobenzene and cyclohexanone [52,53]. According to computational and experimental studies, they proposed that the Pt strongly binded at the four-fold hollow site on POMs in a distorted square-planar geometry of the Keggin type structure with +IV oxidation state of Pt. Recently, using in-situ spectroscopic experiments, they further studied structurally well-defined atomically dispersed $\mathrm{Rh}$ atom supported on PTA for $\mathrm{CO}$ oxidation, and found that the reactions followed an unusual Mars-van-Krevelen pathway for the oxidation of CO [54,55]. The SACs with POM supports have also received attention in computational modeling. Yu et al. [56] recently performed systematic theoretical studies on a series of SACs with PMA for CO oxidation and found interesting trend of PMA-based SACs for this reaction. The development of SACs with POMs support is helpful for the fundamental understanding of catalytic mechanism of singly dispersed atoms on surface and such catalysts have potential for practical applications [57-60].

On the basis of these developments, we have carried out systematic theoretical studies of the geometries, stability and catalytic properties of PTA-supported SACs $\left(\mathrm{M}_{1}\right.$ PTA with $\mathrm{M}=\mathrm{Fe}, \mathrm{Co}, \mathrm{Ni}$; $\mathrm{Ru}, \mathrm{Rh}, \mathrm{Pd}$; Os, Ir and Pt) for 
ethylene epoxidation using density functional theory (DFT). We attempt to screened computationally the most promising SACs for the ethylene epoxidation reaction. We also addressed the adsorption and conversion of $\mathrm{O}_{2}$ and $\mathrm{C}_{2} \mathrm{H}_{4}$ molecules on $\mathrm{M}_{1}$-PTA SACs for the ethylene epoxidation reaction, and found that non-noble metal $\mathrm{SAC}$ of $\mathrm{Fe}_{1}$-PTA was one of the appropriate catalysts with overall robust performance. Moreover, the mechanism of ethylene epoxidation over $\mathrm{Fe}_{1}$-PTA were explored and the highest energy barrier among all the reaction steps was found to be less than $1 \mathrm{eV}$, much lower than the formation of acetaldehyde, suggesting that the $\mathrm{Fe}_{1}$-PTA catalyst was promising for ethylene epoxidation reaction under ambient temperature.

\section{COMPUTATIONAL DETAILS}

Geometrical optimization and energy calculations were performed by using spin-polarized Kahn-Sham formalism of DFT. The generalized gradient approach (GGA) was used with proton balance equation exchange-correlation functional [61], as implemented in the Vienna $A b$ initio Simulation Package (VASP) $[62,63]$. The projector augmented-wave (PAW) potentials were employed to account for the interaction between the valence electrons and ionic core [64-67]. The valence electrons were designated by $5 d^{4} 6 s^{2}$ for $\mathrm{W}, 3 \mathrm{~d}^{6} 4 \mathrm{~s}^{2}$ for $\mathrm{Fe}, 3 \mathrm{~s}^{2} 3 \mathrm{p}^{3}$ for $\mathrm{P}$, $2 s^{2} 2 p^{4}$ for $\mathrm{O}, 2 s^{2} 2 p^{2}$ for $\mathrm{C}$, and $1 \mathrm{~s}^{1}$ for $\mathrm{H}$, respectively. The kinetic cutoff energy of $400 \mathrm{eV}$ was used for the expansion of plane-wave basis sets of the electronic eigenfunctions. A vacuum space of $25 \AA$ was set to avoid interactions between the images of the periodic systems. For geometry optimizations, the Brillion zone integration was calculated with $1 \times 1 \times 1 k$-sampling point to gain the required accuracy. The maximum force for all the ions allowed for relaxation was set to be less than $0.03 \mathrm{eV} \AA^{-1}$. Atomic charges were computed using Bader's atom-inmolecule formalism $[68,69]$.

Following the thermodynamic convention, the binding energy of metal atom $\left(\mathrm{M}_{1}\right)$ on the PTA was defined as $E_{\mathrm{b}}$ $\left(\mathrm{M}_{1}\right)=E\left(\mathrm{M}_{1}-\mathrm{PTA}\right)-E(\mathrm{PTA})-E\left(\mathrm{M}_{1}\right)($ Equation $(1))$. The adsorption energy of molecule $A$ on $\mathrm{M}_{1}$-PTA was defined as $E_{\text {ads }}(\mathrm{A})=E\left(\mathrm{~A} \ldots \mathrm{M}_{1}-\mathrm{PTA}\right)-E(\mathrm{~A})-E\left(\mathrm{M}_{1}-\mathrm{PTA}\right)$ (Equation (2)), where $E\left(\mathrm{M}_{1}-\mathrm{PTA}\right), E\left(\mathrm{M}_{1}\right), E(\mathrm{PTA})$, and $E$ (A) were the total energy of the $\mathrm{M}_{1}$-PTA catalyst, the metal atom, the free PTA cluster, and the non-adsorbed A molecule, respectively.

To explore the reaction transition states of the elementary reaction steps, we used the climbing imagenudged elastic band (CI-NEB) [70,71] and dimer method $[72,73]$. The most elevated images along the least energy barrier were used to determine the transition state (TS). The energy barrier of each elementary reaction was determined by the energy difference between the TS and initial state (IS). All the transition states geometries were confirmed by having one imaginary frequency in vibrational frequency calculations. All the other settings used were the default value of the program.

\section{RESULTS AND DISCUSSION}

In this work, PTA ion $\left(\mathrm{PW}_{12} \mathrm{O}_{40}{ }^{3-}\right)$ was chosen as the support to anchor the single metal atom $\mathrm{M}_{1}$. It is notable that Keggin-type PTA anions are made from $12 \mathrm{MO}_{6}$ octahedrons connecting their corners or edges to a central $\mathrm{PO}_{4}$ tetrahedron. There are various possible coordination positions on the surface oxygen atoms of a PTA cluster: terminal $\left(\mathrm{O}_{\mathrm{t}}\right)$, bridging $\left(\mathrm{O}_{\mathrm{b}}\right)$, and at the sides of the Keggin structure $\left(\mathrm{O}_{c}\right)$. Coordination at these surface oxygen atoms of Keggin-type structure can create single-, two-, three-, and four-fold binding sites for a metal atom. The fully optimized structure of PTA is shown in Fig. 1 and the possible coordination sites are presented in Fig. S1 of the Supplementary Information (SI). The cubic unit cell contains $12 \mathrm{~W}$ atoms, $40 \mathrm{O}$ atoms and one $\mathrm{P}$ atom located in the center. The optimized key geometry parameters are presented in Table S1. The calculated bond lengths of $\mathrm{P}-\mathrm{O}, \mathrm{W}-\mathrm{O}_{c}, \mathrm{~W}-\mathrm{O}_{\text {bri }}$ and $\mathrm{O}_{\text {bri }}-\mathrm{O}_{\text {bri }}$ are $1.54,1.71,1.94$, and $2.69 \AA$, respectively, which are in good agreement with the theoretical and experimental studies [51-53].

\section{Screening $M_{1}$-PTA catalysts for ethylene epoxidation reaction}

To search for an optimal catalytic system for the ethylene epoxidation reaction, a series of transition metals ( $\mathrm{Fe}, \mathrm{Co}$, $\mathrm{Ni}, \mathrm{Ru}, \mathrm{Rh}, \mathrm{Pd}, \mathrm{Os}$, Ir and $\mathrm{Pt}$ ) from the group-VIII elements in the Periodic Table were tested. We have found that all the transition metal atoms studied in this work

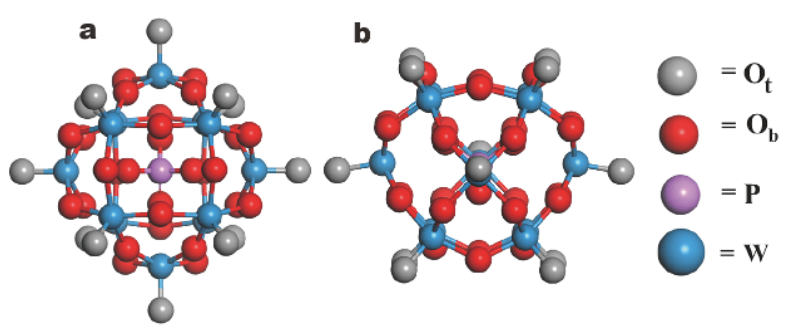

Figure 1 (a) Top and (b) side views of the optimized structure of PTA. The calculated bond lengths of $\mathrm{P}-\mathrm{O}, \mathrm{W}-\mathrm{O}_{c}, \mathrm{~W}-\mathrm{O}_{\text {bri }}$, and $\mathrm{O}_{\text {bri }}-\mathrm{O}_{\text {bri }}$ are $1.54,1.71,1.94$, and $2.69 \AA$, respectively. The grey, red, magenta, and blue color represent terminal oxygen $\left(\mathrm{O}_{\mathrm{t}}\right)$, bridge oxygen $\left(\mathrm{O}_{\mathrm{b}}\right)$, phosphorus $(\mathrm{P})$, and tungsten $(\mathrm{W})$ atom, respectively. 
prefer to anchor on the four-fold hollow $(4 \mathrm{H})$ site of PTA cluster (Fig. S2 and Table S2), consistent with previous theoretical studies on similar $\mathrm{M}_{1}$-PMA systems [56]. The calculated binding energies of the transition metal atoms anchored on $4 \mathrm{H}$ site of PTA cluster, vary from 5 to $11 \mathrm{eV}$ (Table S3) and the binding configurations are shown in Fig. S3. The binding strength of the transition metal atoms with PTA cluster decreases in the order of $\mathrm{Ru}>\mathrm{Os}$ $>\mathrm{Fe}>\mathrm{Co}>\mathrm{Ni}>\mathrm{Ir}>\mathrm{Rh}>\mathrm{Pt}>\mathrm{Pd}$, respectively. That is, for the transition metals in the same period, the adsorption energy (absolute value) decreases with the increased atomic number $(\mathrm{Fe}>\mathrm{Co}>\mathrm{Ni}$; $\mathrm{Ru}>\mathrm{Rh}>\mathrm{Pd}$; $\mathrm{Os}>\mathrm{Ir}>$ $\mathrm{Pt}$ ). Overall, $\mathrm{Fe}, \mathrm{Ru}$, Os have the strongest binding with PTA, compared with the 3d-, 4d-, 5d-row of metals with the same number of valence electrons. The results indicate that the $\mathrm{Ru}$ and Os atoms have strongest interaction with PTA cluster than other transition metal atoms. Among the non-noble metals, Fe atom strongly binds to PTA rendering it a good candidate for constructing chemically stable SACs.

To find the suitable catalyst for ethylene epoxidation, we also analyzed the adsorption energies of $\mathrm{C}_{2} \mathrm{H}_{4}$ and $\mathrm{O}_{2}$ on the M-PTA cluster, because the adsorption of reactants is the key step for heterogeneous reaction. The optimized structures of $\mathrm{C}_{2} \mathrm{H}_{4}$ and $\mathrm{O}_{2}$ on M-PTA cluster are displayed in Figs $\mathrm{S} 4$ and S5, and the adsorption energies are presented in Fig. 2 and Table S3. From these calculation results, $\mathrm{C}_{2} \mathrm{H}_{4}$ adsorbs weakly on $\mathrm{Co}_{1}-\mathrm{PTA}$, with the adsorption energy of only $-0.52 \mathrm{eV}$ and the strongest interaction is found on $\mathrm{Os}_{1}-\mathrm{PTA}$, with an adsorption energy of $-2.45 \mathrm{eV}$. For $\mathrm{O}_{2}$ adsorption on $\mathrm{M}_{1}$ PTA, different configurations are observed. We find that

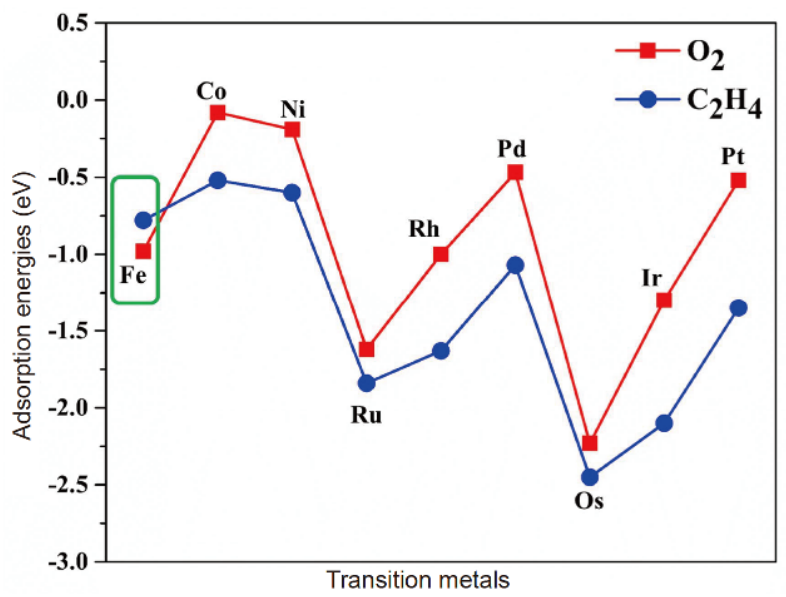

Figure 2 Adsorption energies of $\mathrm{O}_{2}$ (red) and $\mathrm{C}_{2} \mathrm{H}_{4}$ (blue) on $\mathrm{M}_{1}$-PTA $(\mathrm{Fe}, \mathrm{Co}, \mathrm{Ni}, \mathrm{Ru}, \mathrm{Rh}, \mathrm{Pd}$, Os, Ir, and $\mathrm{Pt})\left(\mathrm{M}_{1}=\right.$ group-VIII transition metals).
$\mathrm{O}_{2}$ prefers to lie parallel over the $\mathrm{Fe}, \mathrm{Co}, \mathrm{Ru}$, Os, and $\mathrm{Ir}$ atom with both oxygen atoms of $\mathrm{O}_{2}$ connecting to the metal atom (i.e., side-on coordination), whereas for $\mathrm{Ni}$, $\mathrm{Rh}, \mathrm{Pd}$ and Pt only one oxygen atom connects with the metal atom (i.e. end-on coordination). The strongest interaction is also observed on $\mathrm{Os}_{1}$-PTA with an adsorption energy of $-2.23 \mathrm{eV}$, and the least adsorbed system towards $\mathrm{O}_{2}$ is $\mathrm{Co}_{1}$-PTA. The fact that $\mathrm{O}_{2}$ on $\mathrm{Co}_{1}$-PTA has an adsorption energy of $0.08 \mathrm{eV}$ indicates that $\mathrm{Co}_{1}$-PTA can hardly adsorb $\mathrm{O}_{2}$; this conclusion may be valid even with more accurate calculations including strong electron-correlation and dispersion, which are absent in the current study so that the adsorption energy on $\mathrm{Co}_{1}$-PTA is flawed. As have been shown previously, the different reduced $\mathrm{O}_{2}{ }^{x-}$ species possess different $\mathrm{O}-\mathrm{O}$ distances, which lie around $1.21 \AA$ for $\mathrm{O}_{2}$ (free dioxygen), $1.28 \AA$ for $\mathrm{O}_{2}^{-}$(superoxide), and $1.50 \AA$ for $\mathrm{O}_{2}^{2-}$ (peroxide) [74]. Therefore, we can conclude that the $\mathrm{O}_{2}$ molecule is activated as superoxide, strongly on $\mathrm{Fe}_{1}$-PTA and only weakly on $\mathrm{M}_{1}$-PTA for $\mathrm{M}=\mathrm{Co}, \mathrm{Ni}, \mathrm{Rh}, \mathrm{Pd}, \mathrm{Pt}$; but it is much strongly activated on $\mathrm{M}_{1}$-PTA for $\mathrm{M}=\mathrm{Ru}$, Os, Ir as peroxide.

The transition metals $\mathrm{Co}, \mathrm{Ni}, \mathrm{Ru}, \mathrm{Rh}, \mathrm{Pd}, \mathrm{Os}, \mathrm{Ir}$, and $\mathrm{Pt}$ based PTA catalysts show that the $\mathrm{C}_{2} \mathrm{H}_{4}$ adsorption energy is higher than the corresponding $\mathrm{O}_{2}$ adsorption, which tunes the competition of these species in adsorption. Especially noteworthy is the fact that $\mathrm{O}_{2}$ and $\mathrm{C}_{2} \mathrm{H}_{4}$ adsorption on $\mathrm{Fe}_{1}$-PTA were energetically comparable, while others all favor the adsorption of $\mathrm{C}_{2} \mathrm{H}_{4}$ rather than $\mathrm{O}_{2}$. Therefore, the $\mathrm{Fe}_{1}-\mathrm{PTA}$ SAC shows considerable binding strengths with both $\mathrm{C}_{2} \mathrm{H}_{4}$ and $\mathrm{O}_{2}$, which is necessary for the initiation of ethylene epoxidation reaction. Consequently, to check their catalytic performance for ethylene epoxidation reaction, we studied the reaction mechanism of ethylene epoxidation on $\mathrm{Fe}_{1}$-PTA under normal reaction conditions in details.

\section{Geometry, electronic structure, and stability of $\mathrm{Fe}_{1}-\mathrm{PTA}$}

The optimized geometry of the most stable $\mathrm{Fe}_{1}$-PTA is shown in Fig. 3a. As mentioned before, the Fe atom prefers to locate at the four hollow $(4 \mathrm{H})$ site of the PTA, with the binding energy of $-9.77 \mathrm{eV}$ and $\mathrm{Fe}-\mathrm{O}$ bond lengths of 1.85 and $1.82 \AA$, respectively. According to the Bader charge analysis, the $\mathrm{Fe}$ atom embedded on PTA cluster is positively charged, with atomic charge about $+1.61|\mathrm{e}|$. The four oxygen atoms forming chemical bonds with iron atom gain $0.28,0.30,0.35$, and $0.35 \mathrm{e}^{-}$, respectively. That is, there is substantial electron transfer from $\mathrm{Fe}$ atom to PTA cluster upon Fe binding, which plays an important role for the large stabilization of $\mathrm{Fe}$ 

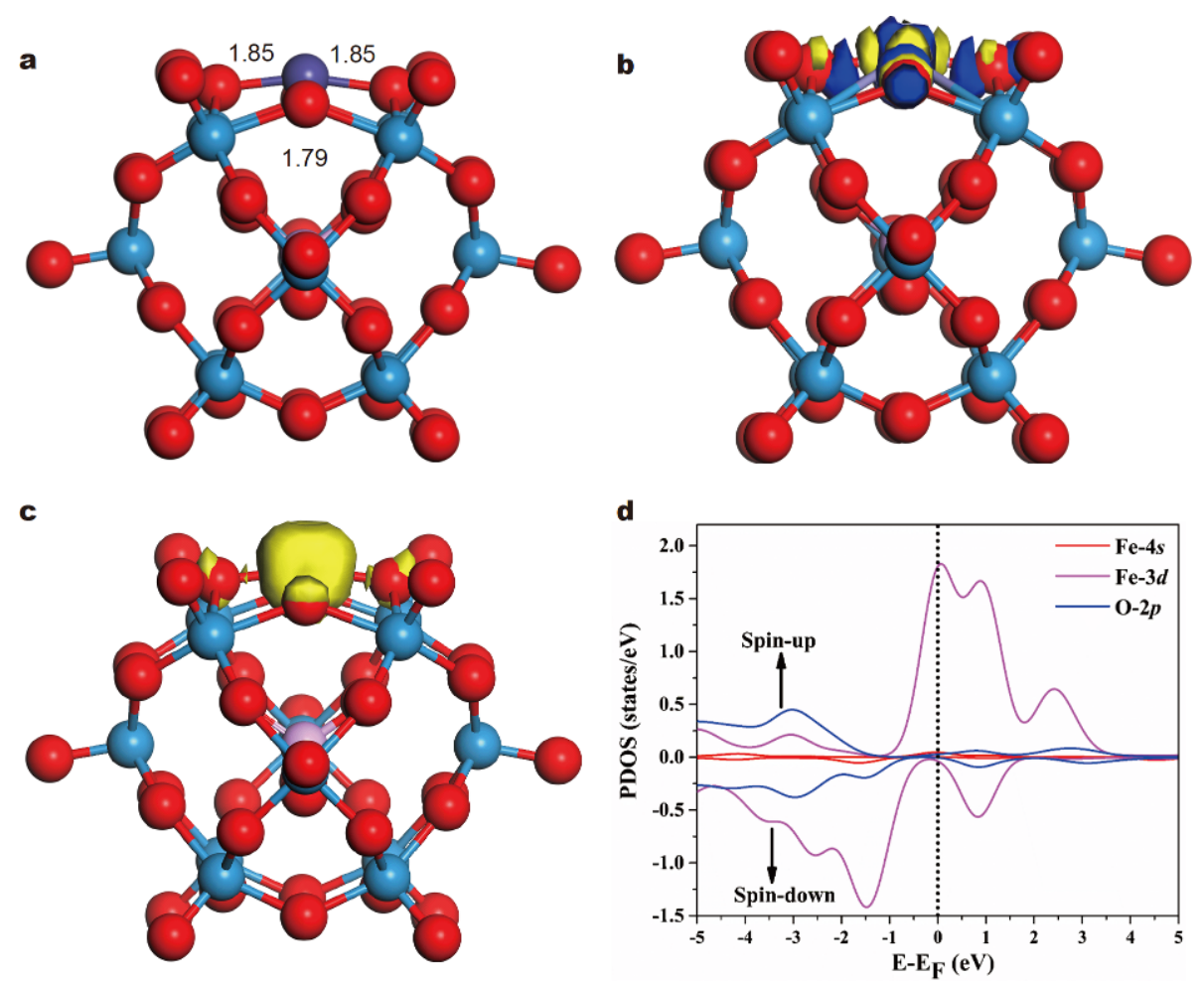

Figure 3 (a) Top view of the optimized geometry of Fe embedded on PTA cluster; (b) charge density difference. For the contour plots, the electron accumulation regions are represented in blue region while the electron depletion regions are shown in yellow. The counter value of the charge density difference is \pm 0.05 a.u. The spin density localization is shown in (c), with the spin density population displayed in yellow. (d) The spin-polarized partial density of states (PDOS) projected on Fe $3 \mathrm{~d}$ and $4 \mathrm{~s}$ (cyan and red) and O 2p (blue) states. The Fermi level was set to zero.

single atom due to both ionic and covalent interaction. Moreover, the positive Bader charges mean that the $\mathrm{Fe}$ atom is in an oxidized form, which might stimulate the catalytic activity of $\mathrm{C}_{2} \mathrm{H}_{4}$ oxidation because of its high chemical potential and high oxidation state. To gain more insight into the nature of the chemical bonding of $\mathrm{Fe}$ atom to PTA, charge density difference plot is presented in Fig. 3b. It is clear that there is a loss of electron density above the embedded $\mathrm{Fe}$ atom, which indicates that the electron density flows from Fe atom towards the nearest $\mathrm{O}$ atoms of PTA. This charge transfer from Fe center to the Keggin type PTA cage mainly accounts for the large binding energy. The spin density population of $\mathrm{Fe}_{1}$-PTA is shown in Fig. 3c, which shows that due to the strong spin polarization and magnetic properties of iron atom, the spin density populations are mainly situated on the Fe atom as well as slightly on the four nearest neighbor oxygen $(\mathrm{O})$ atoms. The magnetic moment of $\mathrm{Fe}$ atom is $2.66 \mu_{B}$ and the oxygen atoms is $-0.03 \mu_{B}$. Such a large spin density population on $\mathrm{Fe}$ site may be one of the key factors to activate the $\mathrm{O}_{2}$ molecule because these free electrons on $\mathrm{Fe}$ are more accessible for $\mathrm{O}_{2}$ coordination and activation.

These results can be further confirmed by spin polarized partial density of states as shown in Fig. 3d. The 3d orbitals of the $\mathrm{Fe}$ atom are found to be strongly mixed with the $2 \mathrm{p}$ orbitals of the PMA oxygen atoms, suggesting that in addition to the ionic interaction, there is strong covalent metal-support interaction (CMSI) between the $\mathrm{Fe}$ and $\mathrm{O}$ atoms at the $4 \mathrm{H}$ site of PTA, as is found in other SACs [10]. The spin-up and spin-down PDOS of the Fe $3 \mathrm{~d}$ orbital are asymmetric near the Fermi level. The presence of Fe 3d orbital near the Fermi level shows high reactivity and may play a role in activating the adsorbates during the catalytic reaction.

\section{Adsorption of $\mathrm{O}_{2}$ and $\mathrm{C}_{2} \mathrm{H}_{4}$ over $\mathrm{Fe}_{1}$-PTA}

To study the mechanism of ethylene epoxidation, we first considered the adsorption of individual $\mathrm{O}_{2}$ and $\mathrm{C}_{2} \mathrm{H}_{4}$ molecules on $\mathrm{Fe}_{1}$-PTA surface. In order to find the most stable configuration of the adsorbed $\mathrm{O}_{2}$ and $\mathrm{C}_{2} \mathrm{H}_{4}$, different adsorption modes were considered. The resulting most stable configuration of the adsorbed $\mathrm{O}_{2}$ on the $\mathrm{Fe}_{1}$ PTA is shown in Fig. 4a. As mentioned earlier, $\mathrm{O}_{2}$ mo- 

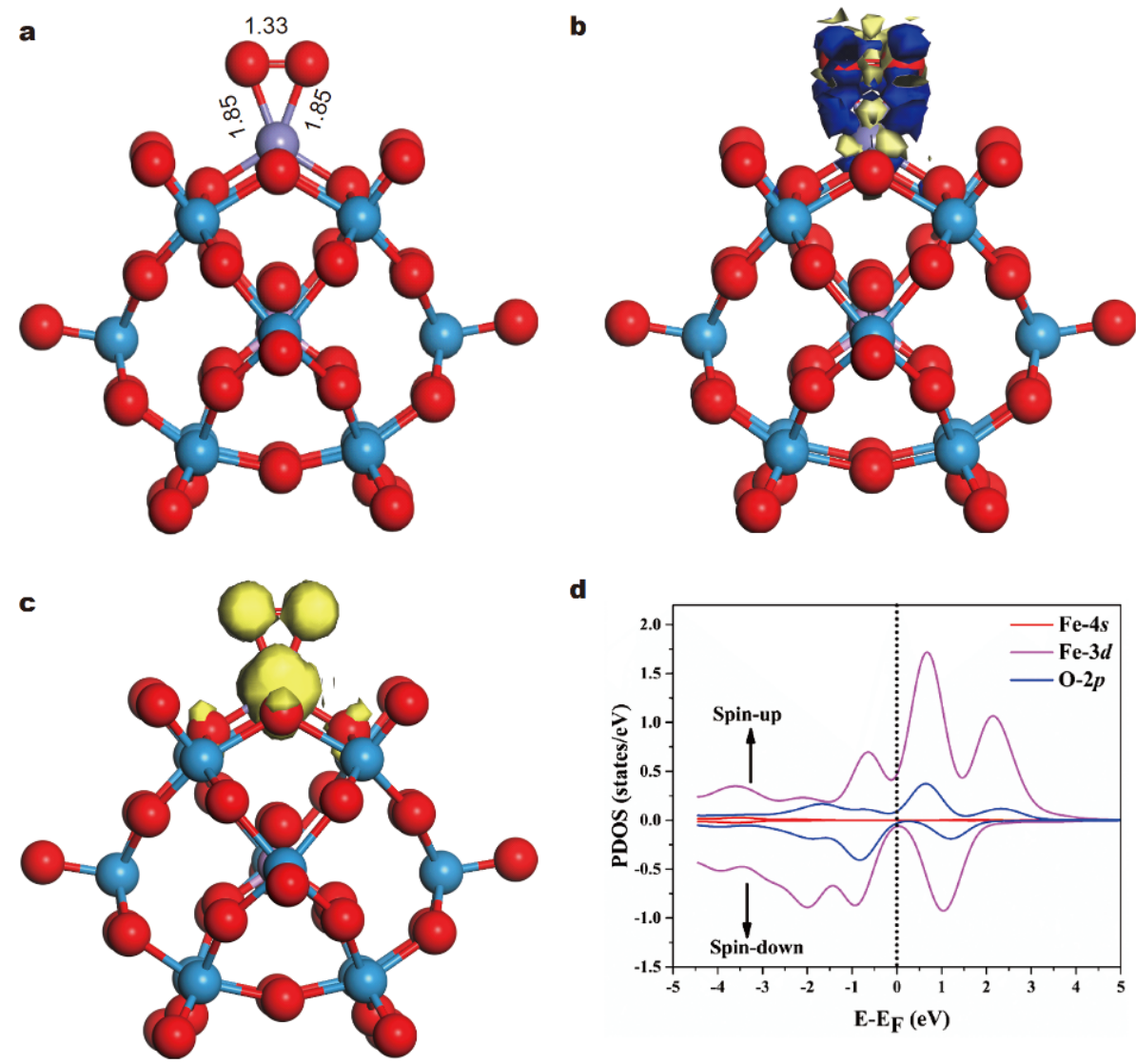

d

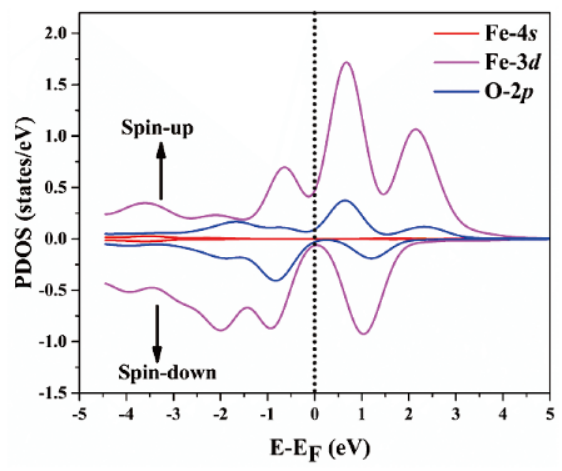

Figure 4 (a) Top view of the optimized geometry of $\mathrm{O}_{2}$ embedded in the $\mathrm{Fe}_{1}$-PTA cluster. (b) Charge density difference. For the contour plots, the electron accumulation regions are represented in blue region while the electron depletion regions are shown in yellow. The counter value of the charge density difference is \pm 0.05 a.u. The spin density localization is shown in (c), with the spin density population displayed in yellow. (d) The spinpolarized PDOS projected on Fe-3d/4s (cyan and red) and adsorbed $\mathrm{O}_{2} 2 \mathrm{p}$ (blue) states. The Fermi level was set to zero.

lecule is adsorbed and activated on the $\mathrm{Fe}$ atom of $\mathrm{Fe}_{1^{-}}$ PTA as a superoxide with a large adsorption energy of $-0.98 \mathrm{eV}$. The interatomic distances are $1.85 \AA$ for $\mathrm{Fe}-\mathrm{O}$, and $1.33 \AA$ for $\mathrm{O}-\mathrm{O}$, which is $0.12 \AA$ longer than those of free $\mathrm{O}_{2}$ molecule. Bader charge analysis shows that $\mathrm{Fe}$ atom remains positively charged $(+0.21|\mathrm{e}|)$ after $\mathrm{O}_{2}$ adsorption, indicating significant charge transfers from $\mathrm{Fe}_{1^{-}}$ PTA to the $\mathrm{O}_{2}$ (ads). We also calculated the charge density difference of $\mathrm{O}_{2}$ on $\mathrm{Fe}_{1}$-PTA as shown in Fig. 4b. The calculated charge density difference confirms that substantial charge transfers from the $\mathrm{Fe}_{1}$-PTA to the adsorbed $\mathrm{O}_{2}$. The surplus charge accumulates between the $\mathrm{O}-\mathrm{O}$ bond and fills the $2 \mathrm{p} \pi^{*}$ antibonding orbital of the $\mathrm{O}_{2}$ molecule, resulting in the $\mathrm{O}-\mathrm{O}$ distance significantly elongated. The spin density population of $\mathrm{O}_{2} \cdots \mathrm{Fe}_{1}-\mathrm{PTA}$ shown in Fig. $4 \mathrm{c}$ demonstrates that the spin distribution of $\mathrm{Fe}_{1}$-PTA is strongly influenced by the adsorbed $\mathrm{O}_{2}$. Remarkably, the magnetic moment decreases (from 2.66 to $1.91 \mu_{\mathrm{B}}$ ) on the $\mathrm{Fe}_{1}$-PTA cluster after $\mathrm{O}_{2}$ adsorption, which suggests the decrease of the unpaired electrons due to the mixing between the Fe $3 \mathrm{~d}$ and $\mathrm{O} 2 \mathrm{p}$ orbitals. The magnetic moment is mainly located around the $\mathrm{Fe}$ $\left(1.91 \mu_{\mathrm{B}}\right)$ atom. To gain better understanding of the electronic structure, the spin-polarized PDOS of $\mathrm{O}_{2} / \mathrm{Fe}_{1^{-}}$ PTA is plotted, as shown in Fig. 4d. It shows that the $3 \mathrm{~d}$ orbitals of Fe are energetically close to the $2 \mathrm{p}$ orbitals of oxygen atom of the adsorbed $\mathrm{O}_{2}$ on the single $\mathrm{Fe}$ atom near the Fermi level, suggesting that there is a relatively strong interaction between the single $\mathrm{Fe}$ atom and the $\mathrm{O}$ atom of the adsorbed $\mathrm{O}_{2}$ molecule. This interaction leads to charge transfer from the $\mathrm{Fe}_{1}$-PTA catalyst to $\mathrm{O}_{2}$. The partial occupation of the $2 \mathrm{p} \pi$-based antibonding molecular orbitals of $\mathrm{O}_{2}$ causes the weakening of $\mathrm{O}-\mathrm{O}$ bonding and strong binding of $\mathrm{O}_{2}$ molecule on the $\mathrm{Fe}_{1}$-PTA.

In addition to the adsorption of oxygen molecule, different adsorption configurations of $\mathrm{C}_{2} \mathrm{H}_{4}$ on $\mathrm{Fe}_{1}$-PTA were also tested with the most stable configuration shown in Fig. 5a. The adsorption energy of $\mathrm{C}_{2} \mathrm{H}_{4}$ on $\mathrm{Fe}_{1}-\mathrm{PTA}$ 

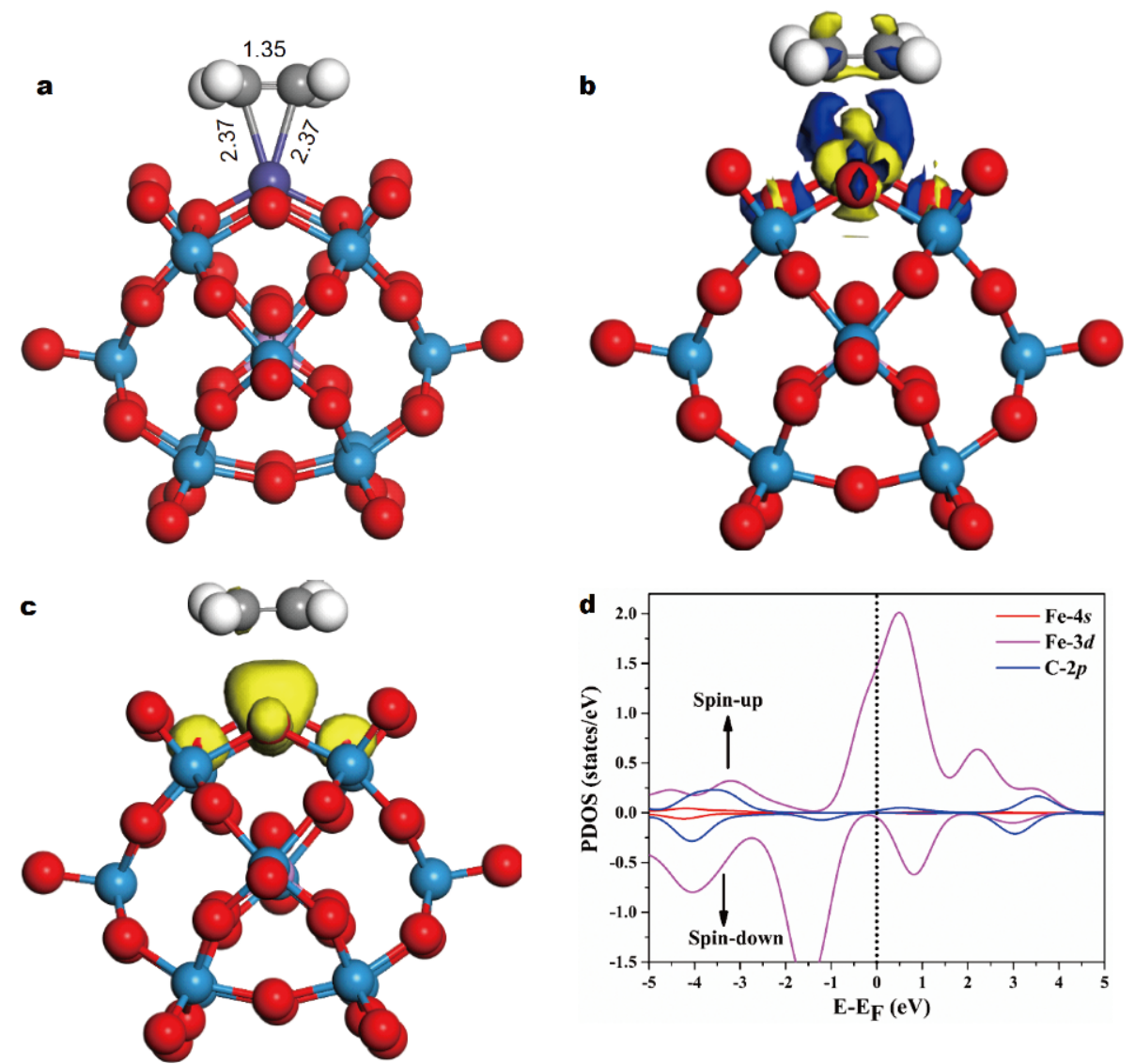

Figure 5 (a) Top view of the optimized geometry of $\mathrm{C}_{2} \mathrm{H}_{4}$ adsorbed on $\mathrm{Fe}_{1}$-PTA cluster. (b) Charge density difference. For the contour plots, the electron accumulation regions are represented in blue region while the electron depletion regions are shown in yellow. The counter value of the charge density difference is \pm 0.05 a.u. The spin density localization is shown in (c), with the spin density population displayed in yellow. The spin-polarized PDOS projected on Fe 3d/4s (cyan and red) and C 2p (blue) states (d). The Fermi level was set to zero.

was calculated as $-0.78 \mathrm{eV}$, which was $(0.20 \mathrm{eV})$ less than that of $\mathrm{O}_{2}$ adsorption, indicating that the adsorption of $\mathrm{O}_{2}$ was more preferred than that of $\mathrm{C}_{2} \mathrm{H}_{4}$ although the difference is small. The interatomic bond distances are $2.37 \AA$ for $\mathrm{Fe}-\mathrm{C}$, and $1.35 \AA$ for $\mathrm{C}-\mathrm{C}$, which is $0.02 \AA$ longer than that in free ethylene molecule. From Bader charge analysis, the adsorbed $\mathrm{C}_{2} \mathrm{H}_{4}$ molecule gains $0.12|\mathrm{e}|$ from the $\mathrm{Fe}_{1}$-PTA due to charge transfer. The charge density difference depicted in Fig. $5 b$ indeed shows that the charge density accumulates between the $\mathrm{Fe}$ and $\mathrm{C}$ atoms and the charge density decreases between the two carbon atoms, as seen by the blue and yellow areas, respectively. The spin density population of the system with $\mathrm{C}_{2} \mathrm{H}_{4}$ molecule adsorbed on the $\mathrm{Fe}_{1}$-PTA surface is shown in Fig. $5 \mathrm{c}$. The spin density is mainly localized on the $\mathrm{Fe}_{1^{-}}$ PTA, indicating weak interaction between $\mathrm{C}_{2} \mathrm{H}_{4}$ and $\mathrm{Fe}_{1^{-}}$ PTA. The magnetic moment is slightly decreased from 2.66 to $2.50 \mu_{\mathrm{B}}$ on the $\mathrm{Fe}_{1}$-PTA cluster after $\mathrm{C}_{2} \mathrm{H}_{4}$ adsorption, which agrees with the weak interaction between the Fe atom and $\mathrm{C}_{2} \mathrm{H}_{4}$ molecule. The PDOS projected onto the adsorbed $\mathrm{C}_{2} \mathrm{H}_{4}$ molecule, as well as the $\mathrm{Fe} 4 \mathrm{~s} / 3 \mathrm{~d}$ and $\mathrm{C} 2 \mathrm{p}$ orbitals is shown in Fig. $5 \mathrm{~d}$, which confirms the orbital mixing between the $\mathrm{C} 2 \mathrm{p}$ and Fe $3 \mathrm{~d}$ orbitals, although it is not significant due to the large distance ( $2.37 \AA$ ) between them. In addition, small overlap is observed between the Fe 3d orbital and $\mathrm{C} 2 \mathrm{p}$ orbital near the Fermi level, indicating the weak interaction between $\mathrm{C}_{2} \mathrm{H}_{4}$ and $\mathrm{Fe}_{1}$-PTA. Compared with the spin-polarized PDOS of the $\mathrm{Fe}_{1}$-PTA cluster as presented in the Fig. $2 \mathrm{~d}$, the $3 \mathrm{~d}$ orbitals of Fe near the Fermi level slightly decrease after the adsorption of $\mathrm{C}_{2} \mathrm{H}_{4}$ on $\mathrm{Fe}_{1}$-PTA. These results are confirmed by the electron density difference and spin density localization.

Reaction mechanism of ethylene epoxidation on $\mathrm{Fe}_{1}$-PTA To explore possible reaction mechanism for the oxidation of ethylene to ethylene oxide by $\mathrm{O}_{2}$ molecule on $\mathrm{Fe}_{1}-\mathrm{PTA}$, we have considered the following three steps: 
Step 1: $[\mathrm{Fe}]+\mathrm{O}_{2} \rightarrow[\mathrm{Fe}] \mathrm{O}_{2}{ }^{*}$;

Step 2: $[\mathrm{Fe}] \mathrm{O}_{2}{ }^{*}+\mathrm{C}_{2} \mathrm{H}_{4} \rightarrow[\mathrm{Fe}] \mathrm{O}^{*} \cdots \mathrm{O}^{*} \cdot \mathrm{C}_{2} \mathrm{H}_{4} \rightarrow[\mathrm{Fe}] \mathrm{O}^{*}+\mathrm{C}_{2} \mathrm{H}_{4} \mathrm{O}$; Step 3: $[\mathrm{Fe}] \mathrm{O}^{*}+\mathrm{C}_{2} \mathrm{H}_{4} \rightarrow[\mathrm{Fe}] \mathrm{O}^{*} \cdots \mathrm{C}_{2} \mathrm{H}_{4} \rightarrow[\mathrm{Fe}]+\mathrm{C}_{2} \mathrm{H}_{4} \mathrm{O}$; where $[\mathrm{Fe}]$ represents the active site of the $\mathrm{Fe}_{1}$-PTA SAC.

Fig. 6 shows the calculated energy profile of the proposed reaction mechanism for ethylene epoxidation on $\mathrm{Fe}_{1}-\mathrm{PTA}$, and the IS, intermediate (IM), TS, and final structure (FS) are shown in Fig. 7. The step 1 is the adsorption of dioxygen molecule on the $\mathrm{Fe}_{1}$-PTA surface, as discussed above (see Fig. 4). Because of the strong bonding of the PTA surface terminal-oxo to $\mathrm{W}$ and the limited space around the isolated single $\mathrm{Fe}$ atom embedded on PTA, it is rather hard to extract the surface oxygen atoms or adsorb both $\mathrm{O}_{2}$ and $\mathrm{C}_{2} \mathrm{H}_{4}$ on $\mathrm{Fe}$ atom simultaneously, which makes the well-known Mars-van Krevelen and Langmuir-Hinshelwood mechanisms highly unfavorable compared with the Eley-Rideal mechanism. Therefore, we only consider the adsorbed dioxygen molecule (i.e., $\mathrm{O}_{2}^{-}$) on $\mathrm{Fe}_{1}$-PTA surface interacting with an ethylene $\left(\mathrm{C}_{2} \mathrm{H}_{4}\right)$ molecule via the Eley-Rideal mechanism to form an ethylene oxide $\left(\mathrm{C}_{2} \mathrm{H}_{4} \mathrm{O}\right)$ molecule and an iron-oxo complex $([\mathrm{Fe}] \mathrm{O})$ in step 2. The IM1 of $\mathrm{C}_{2} \mathrm{H}_{4}$ attacking $\mathrm{O}_{2}$ adsorbed on $\mathrm{Fe}_{1^{-}}$ PTA is calculated to be $0.18 \mathrm{eV}$ above the initial state of $\mathrm{O}_{2} \cdots \mathrm{Fe}_{1}$-PTA (IS). This process is feasible thermodynamically because $\mathrm{O}_{2}$ adsorption on $\mathrm{Fe}_{1}$-PTA is strongly exothermic by $-0.98 \mathrm{eV}$. In Fig. 6 , the adsorbed structure of $\mathrm{O}_{2}$ on $\mathrm{Fe}_{1}$-PTA is chosen as IS, in which the $\mathrm{O}-\mathrm{O}$ bond distance is elongated to $1.31 \AA$ when compared with free $\mathrm{O}_{2}$. The reaction intermediate IM1 corresponds to $\mathrm{C}_{2} \mathrm{H}_{4}$ weakly adsorbed on the chemisorbed $\mathrm{O}_{2}$ molecule, and the adsorption of $\mathrm{O}_{2}$ is converted from

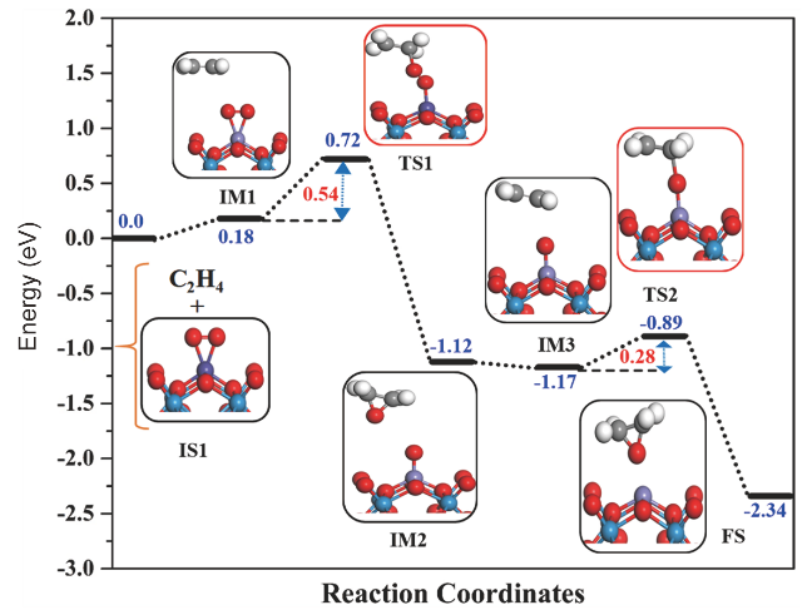

Figure 6 Schematic energy profile for the epoxidation of ethylene. All DFT energies are in $\mathrm{eV}$.
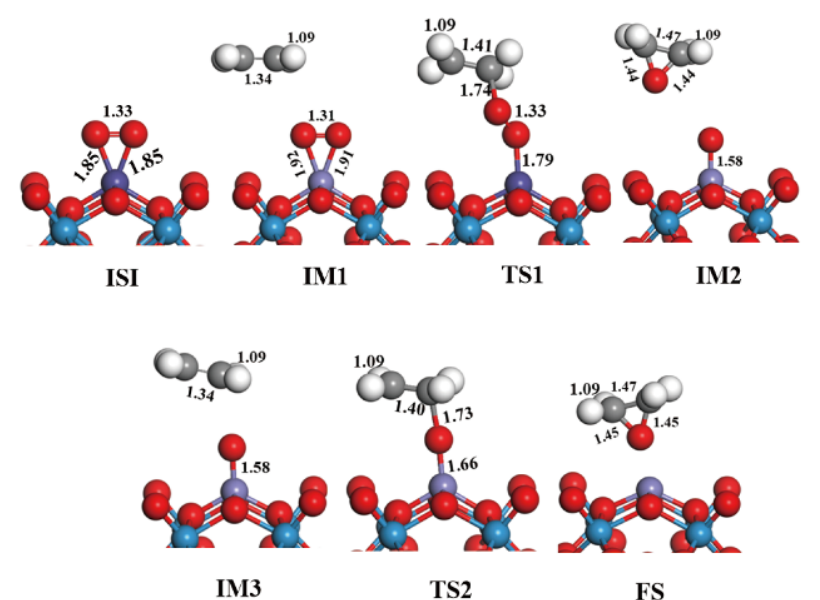

Figure 7 Optimized geometries of IS, TS, IM, and FS of the ethylene oxidation on $\mathrm{Fe}_{1}$-PTA. All the calculated bond lengths are given in $\AA$.

side-on in IM1 to end-on mode to form [Fe]-O-O $\cdots$ $\mathrm{C}_{2} \mathrm{H}_{4}$, which leads to the formation of IM2 through the TS1. Here TS1 has an activation energy barrier of $0.54 \mathrm{eV}$ with one imaginary frequency of $381 \mathrm{i} \mathrm{cm}^{-1}$, which is associated with the formation of carbon-oxygen $(\mathrm{C}-\mathrm{O})$ bond and the dissociation of oxygen-oxygen $(\mathrm{O}-\mathrm{O})$ bond. At the TS1, the bond length of the $\mathrm{O}-\mathrm{O}$ increases from 1.31 to $1.33 \AA$ and the bond length of $\mathrm{C}-\mathrm{C}$ in ethylene is elongated from 1.34 to $1.41 \AA$, respectively. That is, an oxygen transfer process occurs from $\mathrm{O}_{2}$ adsorbed on $\mathrm{Fe}_{1^{-}}$PTA to $\mathrm{C}_{2} \mathrm{H}_{4}$ molecule and the formation of new $\mathrm{C}-\mathrm{O}$ bond (1.74 $\AA$ ) gives rise to the IM2. In IM2, the bond length of $\mathrm{C}-\mathrm{C}$ in $\mathrm{C}_{2} \mathrm{H}_{4} \mathrm{O}$ molecule is elongated to $1.47 \AA$, indicating a single $\mathrm{C}-\mathrm{C}$ bond with calculated Wiberg bond order of 1.32. In the final step, the Fe-oxo complex directly interacts with another $\mathrm{C}_{2} \mathrm{H}_{4}$ molecule and forms a new ethylene oxide $\left(\mathrm{C}_{2} \mathrm{H}_{4} \mathrm{O}\right)$ molecule through the TS2. Here TS2 has an activation energy barrier of only $0.28 \mathrm{eV}$ with one imaginary frequency of $443 \mathrm{icm}^{-1}$, which is associated with the formation of $\mathrm{C}-\mathrm{O}$ bond and the dissociation of $\mathrm{Fe}-\mathrm{O}$ bond. The formation of new $\mathrm{C}-\mathrm{O}$ bond $(1.73 \AA$ A $)$ gives rise to the FS.

The spin magnetic moments can provide useful information for the elementary steps involved in the ethylene epoxidation reaction. From the calculated spin magnetic moments, the $\mathrm{Fe}_{1}$-PTA catalyst has a spin magnetic moment of $3.85 \mu_{\mathrm{B}}$ at the $\mathrm{Fe}^{\delta+}$ active center. The TS and desorption species are the most important ones in this reaction. In IS1, when one electron is transferred from $\mathrm{Fe}^{\delta+}$ to $\mathrm{O}_{2}$ to form $\mathrm{O}_{2}^{-}$, the magnetic moment of $\mathrm{Fe}^{\delta+}$ is $2.02 \mu_{\mathrm{B}}$, when $\mathrm{C}_{2} \mathrm{H}_{4}$ physisorbed over the $\mathrm{O}_{2} / \mathrm{Fe}_{1}$ PTA. However, the spin magnetic moment of IM1 is 
quenched to $0.71 \mu_{\mathrm{B}}$, indicating that $\mathrm{Fe}^{\delta+}$ is reduced. The spin magnetic moment is $0.81 \mu_{\mathrm{B}}$ for TS1 and $0.69 \mu_{\mathrm{B}}$ for IM2, due to the strong interaction between the second $\mathrm{C}_{2} \mathrm{H}_{4}$ molecule and $\mathrm{OFe}_{1}$-PTA. In TS2, the Fe-oxo interacts with ethylene molecule and $\mathrm{Fe}^{\delta+}$ is oxidized, with the magnetic moment increasing to $1.22 \mu_{\mathrm{B}}$. With desorption of ethylene epoxide molecule, the magnetic moments of $\mathrm{Fe}^{\delta+}$ in FS increase to $3.85 \mu_{\mathrm{B}}$ and the $\mathrm{Fe}^{\delta+}$ is again oxidized. We have also calculated the PDOS of all the elementary steps and the results are presented in Fig. S6. It can be seen that Fe $3 \mathrm{~d}$ orbital plays an important role in changing the magnetic moment of $\mathrm{Fe}$ in all the elementary steps near the Fermi level.

In addition, other possible oxidation products (such as acetaldehyde) was also examined in this work. It is found that the formation of acetaldehyde from the IM of ethylene epoxidation has an activation energy barrier of $1.47 \mathrm{eV}$ (TS with $790 \mathrm{i} \mathrm{cm}^{-1}$ ). It follows that the formation of acetaldehyde is not favorable kinetically despite the large exothermicity of $1.39 \mathrm{eV}$ (Fig. S7).

\section{CONCLUSIONS}

In this work, the geometrical structures, electronic structures, and catalytic activity for ethylene epoxidation of single transition metal atom $(\mathrm{Fe}, \mathrm{Co}, \mathrm{Ni}, \mathrm{Ru}, \mathrm{Rh}, \mathrm{Pd}$, Os, Ir, and Pt) supported on PTA cluster were systematically investigated by using the first principles calculations. The results show that the transition metal atoms prefer to anchor at the four hollow $(4 \mathrm{H})$ site of the PTA cluster, with $\mathrm{Fe}, \mathrm{Ru}$, Os atoms having the strongest binding with PTA in each row of the transition metals. We have then studied their catalytic activities by using ethylene epoxidation as an illustrative reaction. For this purpose, the adsorption of $\mathrm{C}_{2} \mathrm{H}_{4}$ and $\mathrm{O}_{2}$ molecules on the $\mathrm{M}_{1}$-PTA (Fe, Co, Ni, Ru, Rh, Pd, Os, Ir, and Pt) systems are considered and detailed calculations reveal that the $\mathrm{Fe}_{1}$-PTA system has comparable adsorption energy to $\mathrm{C}_{2} \mathrm{H}_{4}$ and $\mathrm{O}_{2}$ molecules. The facile conversion between $\mathrm{Fe}^{+3}$ and $\mathrm{Fe}^{+2}$ oxidation state renders the $\mathrm{Fe}_{1}$-PTA system robust catalytic activity for ethylene epoxidation. It has been found that the anchored $\mathrm{Fe}$ atom is positively charged and there are charge transfer from iron metal atom to PTA cluster and orbital mixing between $\mathrm{Fe}$ and surface oxygen, which make the $\mathrm{Fe}_{1}$ - $\mathrm{PTA}$ catalyst stable.

The first step of ethylene epoxidation is the adsorption of dioxygen molecule on the $\mathrm{Fe}_{1}$-PTA cluster, and the adsorbed $\mathrm{O}_{2}$ molecule then interacts with the $\mathrm{C}_{2} \mathrm{H}_{4}$ molecule directly via Eley-Rideal mechanism. The second step involves the interaction of the first ethylene molecule with the adsorbed $\mathrm{O}_{2}$ on $\mathrm{Fe}$ complex and the formation of an ethylene oxide $\left(\mathrm{C}_{2} \mathrm{H}_{4} \mathrm{O}\right)$ molecule and an [Fe]O complex with a small activation energy barrier of $0.54 \mathrm{eV}$. The final step of the reaction reveals that Fe-oxo complex directly interacts with the second $\mathrm{C}_{2} \mathrm{H}_{4}$ molecule and generates another ethylene oxide $\left(\mathrm{C}_{2} \mathrm{H}_{4} \mathrm{O}\right)$ molecule with a rather small energy barrier of $0.28 \mathrm{eV}$. The potentially competing pathway of the formation of acetaldehyde is not kinetically favorable.

These results suggest that the $\mathrm{Fe}_{1}$-PTA SAC is a robust system for ethylene epoxidation. As iron is a non-noble metal, the current finding is helpful for guiding future experimental exploration of such catalysts for ethylene epoxidation. It seems possible that through systematic computational screening and modeling, stable and efficient non-noble metal catalysts can be developed for various important catalytic reactions because of the easy control of the electronic structure of the active center through coordination chemistry $[75,76]$. SACs thus serve as a bridge between homogeneous/biological and heterogeneous catalysts.

\section{Received 10 March 2020; accepted 19 May 2020;}

published online 25 May 2020

1 Qiao B, Wang A, Yang X, et al. Single-atom catalysis of CO oxidation using $\mathrm{Pt}_{1} / \mathrm{FeO}_{x}$. Nat Chem, 2011, 3: 634-641

2 Yang XF, Wang A, Qiao B, et al. Single-atom catalysts: a new frontier in heterogeneous catalysis. Acc Chem Res, 2013, 46: 17401748

3 Wang A, Li J, Zhang T. Heterogeneous single-atom catalysis. Nat Rev Chem, 2018, 2: 65-81

4 Liu J. Catalysis by supported single metal atoms. ACS Catal, 2017, 7: $34-59$

5 Liu JC, Tang Y, Wang YG, et al. Theoretical understanding of the stability of single-atom catalysts. Natl Sci Rev, 2018, 5: 638-641

6 Liu JC, Wang YG, Li J. Toward rational design of oxide-supported single-atom catalysts: atomic dispersion of gold on ceria. J Am Chem Soc, 2017, 139: 6190-6199

7 Giannakakis G, Flytzani-Stephanopoulos M, Sykes ECH. Singleatom alloys as a reductionist approach to the rational design of heterogeneous catalysts. Acc Chem Res, 2019, 52: 237-247

8 Hülsey MJ, Zhang J, Yan N. Harnessing the wisdom in colloidal chemistry to make stable single-atom catalysts. Adv Mater, 2018, 30: 1802304

9 Qin R, Liu P, Fu G, et al. Strategies for stabilizing atomically dispersed metal catalysts. Small Methods, 2018, 2: 1700286

10 Qiao B, Liang JX, Wang A, et al. Ultrastable single-atom gold catalysts with strong covalent metal-support interaction (CMSI). Nano Res, 2015, 8: 2913-2924

11 Lin J, Wang A, Qiao B, et al. Remarkable performance of $\mathrm{Ir}_{1} / \mathrm{FeO}_{x}$ single-atom catalyst in water gas shift reaction. J Am Chem Soc, 2013, 135: 15314-15317

12 Long B, Tang Y, Li J. New mechanistic pathways for CO oxidation catalyzed by single-atom catalysts: supported and doped $\mathrm{Au}_{1} /$ $\mathrm{ThO}_{2}$. Nano Res, 2016, 9: 3868-3880

13 Liang JX, Yang XF, Wang A, et al. Theoretical investigations of 
non-noble metal single-atom catalysis: $\mathrm{Ni}_{1} / \mathrm{FeO}_{x}$ for $\mathrm{CO}$ oxidation. Catal Sci Technol, 2016, 6: 6886-6892

14 Deng $\mathrm{T}$, Zheng $\mathrm{W}$, Zhang $\mathrm{W}$. Increasing the range of non-noblemetal single-atom catalysts. Chin J Catal, 2017, 38: 1489-1497

15 Liu W, Zhang H, Li C, et al. Non-noble metal single-atom catalysts prepared by wet chemical method and their applications in electrochemical water splitting. J Energy Chem, 2020, 47: 333-345

16 Gebbink R J K, Moret M E. Non-noble Metal Catalysis: Molecular Approaches and Reactions. Weinheim: John Wiley \& Sons, 2019

17 Lv CQ, Liu JH, Guo Y, et al. DFT $+U$ investigation on the adsorption and initial decomposition of methylamine by a Pt singleatom catalyst supported on rutile (110) $\mathrm{TiO}_{2}$. Appl Surf Sci, 2016, 389: 411-418

18 Song Z, Li W, Niu F, et al. A novel method to decorate Au clusters onto graphene via a mild Co-reduction process for ultrahigh catalytic activity. J Mater Chem A, 2017, 5: 230-239

19 Kwak JH, Lee J, Szanyi J, et al. Modification of the acid/base properties of $\gamma-\mathrm{Al}_{2} \mathrm{O}_{3}$ by oxide additives: An ethanol TPD investigation. Catal Today, 2016, 265: 240-244

20 Peterson EJ, DeLaRiva AT, Lin S, et al. Low-temperature carbon monoxide oxidation catalysed by regenerable atomically dispersed palladium on alumina. Nat Commun, 2014, 5: 4885

21 Li J, Liu J, Zhang T. Preface to the special issue of the international symposium on single-atom catalysis (ISSAC-2016). Chin J Catal, 2017, 38: 1431

22 Liang JX, Wang YG, Yang XF, et al. Recent advances in singleatom catalysis. Encyclopedia Inorg Bioinorg Chem, 2011, 1-11

23 Zheng N, Zhang T. Preface: single-atom catalysts as a new generation of heterogeneous catalysts. Natl Sci Rev, 2018, 5: 625

24 Liu L, Corma A. Metal catalysts for heterogeneous catalysis: from single atoms to nanoclusters and nanoparticles. Chem Rev, 2018, 118: 4981-5079

25 Chen Y, Ji S, Chen C, et al. Single-atom catalysts: synthetic strategies and electrochemical applications. Joule, 2018, 2: 1242-1264

26 Jones TE, Wyrwich R, Böcklein S, et al. The selective species in ethylene epoxidation on silver. ACS Catal, 2018, 8: 3844-3852

27 Özbek MO, Önal I, van Santen RA. Ethylene epoxidation catalyzed by silver oxide. ChemCatChem, 2011, 3: 150-153

28 Christopher P, Linic S. Engineering selectivity in heterogeneous catalysis: Ag nanowires as selective ethylene epoxidation catalysts. J Am Chem Soc, 2008, 130: 11264-11265

29 Linic S, Barteau MA. Control of ethylene epoxidation selectivity by surface oxametallacycles. J Am Chem Soc, 2003, 125: 4034-4035

30 van Hoof AJF, Filot IAW, Friedrich $\mathrm{H}$, et al. Reversible restructuring of silver particles during ethylene epoxidation. ACS Catal, 2018, 8: 11794-11800

31 López X, Carbó JJ, Bo C, et al. Structure, properties and reactivity of polyoxometalates: A theoretical perspective. Chem Soc Rev, 2012, 41: 7537

32 Hossain MM, Aldous L. Polyoxometalates as solution-phase electrocatalytic mediators for reduced electrode fouling and the improved oxidative response of phenols. Electrochem Commun, 2016, 69: 32-35

33 Mei Y, Huang W, Yang Z, et al. Ion-pairing and aggregation of ionic liquid-neutralized polyoxometalate salts in aqueous solutions. Fluid Phase Equilib, 2016, 425: 31-39

34 Wen S, Guan W, Wang J, et al. Theoretical investigation of structural and electronic propertyies of $\left[\mathrm{PW}_{12} \mathrm{O}_{40}\right]^{3-}$ on graphene layer. Dalton Trans, 2012, 41: 4602-4607

35 Xie L, Jiang R, Zhu F, et al. Application of functionalized magnetic nanoparticles in sample preparation. Anal Bioanal Chem, 2014, 406: $377-399$

36 Hill CL. Introduction: Polyoxometalates multicomponent molecular vehicles to probe fundamental issues and practical problems. Chem Rev, 1998, 98: 1-2

37 Dolbecq A, Dumas E, Mayer CR, et al. Hybrid organic-inorganic polyoxometalate compounds: from structural diversity to applications. Chem Rev, 2010, 110: 6009-6048

38 Zhang Z, Wang YL, Yang GY. Two inorganic-organic hybrid polyoxotungstates constructed from tetra-ZrIV-substituted sandwich-type germanotungstates functionalized by tris ligand. InOrg Chem Commun, 2017, 85: 32-36

39 Copéret C, Comas-Vives A, Conley MP, et al. Surface organometallic and coordination chemistry toward single-site heterogeneous catalysts: strategies, methods, structures, and activities. Chem Rev, 2016, 116: 323-421

40 Laird T. Dangers of the unknown. Org Process Res Dev, 2003, 7: 225

41 Tanielyan SK, Augustine RL, Marin N, et al. Anchored Wilkinson catalyst. ACS Catal, 2011, 1: 159-169

42 Song CE, Lee SG. Supported chiral catalysts on inorganic materials. Chem Rev, 2002, 102: 3495-3524

$43 \mathrm{Wu} \mathrm{Y}$, Wang D, Li Y. Understanding of the major reactions in solution synthesis of functional nanomaterials. Sci China Mater, 2016, 59: 938-996

44 Allen DT. Luque, Yan, You: 2018 winners of the ACS Sustainable Chemistry \& Engineering lectureship awards. ACS Sustain Chem Eng, 2017, 5: 7450

45 Roithova J, Schroder D. Selective activation of alkanes by gas-phase metal ions. Chem Rev, 2010, 110: 1170-1211

46 Mallat T, Baiker A. Oxidation of alcohols with molecular oxygen on solid catalysts. Chem Rev, 2004, 104: 3037-3058

47 Zhang Z, Qu Y, Wang S, et al. Theoretical study on the mechanisms of the conversion of methyl lactate over sodium polyphosphate catalyst. J Mol Catal A-Chem, 2010, 323: 91-100

48 Yang X, Waters T, Wang XB, et al. Photoelectron spectroscopy of free polyoxoanions $\mathrm{Mo}_{6} \mathrm{O}_{19}{ }^{2-}$ and $\mathrm{W}_{6} \mathrm{O}_{19}{ }^{2-}$ in the gas phase. J Phys Chem A, 2004, 108: 10089-10093

49 Li J. Electronic structures, (d-p) $\pi$ conjugation effects, and spectroscopic properties of polyoxometalates: $\mathrm{M}_{6} \mathrm{O}_{19}{ }^{2-}(\mathrm{M}=\mathrm{Cr}, \mathrm{Mo}$, W). J Cluster Sci, 2002, 13: 137-163

50 López X, Maestre JM, Bo C, et al. Electronic properties of polyoxometalates: A DFT study of $\alpha / \beta-\left[\mathrm{XM}_{12} \mathrm{O}_{40}\right]^{n-}$ relative stability ( $\mathrm{M}=\mathrm{W}, \mathrm{Mo}$ and $\mathrm{X}$ a main group element). J Am Chem Soc, 2001, 123: $9571-9576$

$51 \mathrm{He} \mathrm{P}, \mathrm{Xu} \mathrm{B}, \mathrm{Xu} \mathrm{X}$, et al. Surfactant encapsulated palladium-polyoxometalates: controlled assembly and their application as singleatom catalysts. Chem Sci, 2016, 7: 1011-1015

52 Zhang B, Asakura H, Yan N. Atomically dispersed rhodium on self-assembled phosphotungstic acid: structural features and catalytic CO oxidation properties. Ind Eng Chem Res, 2017, 56: 35783587

53 Zhang B, Asakura H, Zhang J, et al. Stabilizing a platinum ${ }_{1}$ singleatom catalyst on supported phosphomolybdic acid without compromising hydrogenation activity. Angew Chem Int Ed, 2016, 55: 8319-8323

54 Hülsey MJ, Zhang B, Ma Z, et al. In situ spectroscopy-guided engineering of rhodium single-atom catalysts for $\mathrm{CO}$ oxidation. Nat Commun, 2019, 10: 1330

55 Zhang B, Sun G, Ding S, et al. Atomically dispersed $\mathrm{Pt}_{1}-$ poly- 
oxometalate catalysts: How does metal-support interaction affect stability and hydrogenation activity? J Am Chem Soc, 2019, jacs.9b00486

56 Yu MA, Feng Y, Gao L, et al. Phosphomolybdic acid supported single-metal-atom catalysis in CO oxidation: First-principles calculations. Phys Chem Chem Phys, 2018, 20: 20661-20668

57 Kozhevnikov IV. Catalysis by heteropoly acids and multicomponent polyoxometalates in liquid-phase reactions. Chem Rev, 1998, 98: 171-198

58 Yue ZC, Du HJ, Li L, et al. Synthesis and characterization of two new polymolybdate clusters containing chlorine based on MoPOMs and N-heterocycle templates. Synthesis Reactivity InOrg Metal-Org Nano-Metal Chem, 2014, 44: 678-686

59 Tessonnier JP, Goubert-Renaudin S, Alia S, et al. Structure, stability, and electronic interactions of polyoxometalates on functionalized graphene sheets. Langmuir, 2013, 29: 393-402

60 Matthey J, Aesar A. PGMs in the lab: Platinum group metals in polyoxometalates. Platinum Met Rev, 2014, 58: 40-41

61 Perdew JP, Burke K, Ernzerhof M. Generalized gradient approximation made simple. Phys Rev Lett, 1997, 77: 3865-3868

62 Kresse G, Furthmüller J. Efficiency of ab-initio total energy calculations for metals and semiconductors using a plane-wave basis set. Comput Mater Sci, 1996, 6: 15-50

63 Kresse G, Hafner J. Ab initio molecular dynamics for liquid metals. Phys Rev B, 1993, 47: 558-561

64 Kresse G. Ab initio molecular dynamics for liquid metals. J NonCrystalline Solids, 1995, 192-193: 222-229

65 Kresse G, Joubert D. From ultrasoft pseudopotentials to the projector augmented-wave method. Phys Rev B, 1999, 59: 1758-1775

66 Blöchl PE. Projector augmented-wave method. Phys Rev B, 1994, 50: $17953-17979$

67 Perdew JP, Wang Y. Accurate and simple analytic representation of the electron-gas correlation energy. Phys Rev B, 1992, 45: 1324413249

68 Tang W, Sanville E, Henkelman G. A grid-based Bader analysis algorithm without lattice bias. J Phys-Condens Matter, 2009, 21: 084204

$69 \mathrm{Yu} \mathrm{M}$, Trinkle DR. Accurate and efficient algorithm for Bader charge integration. J Chem Phys, 2011, 134: 064111

70 Henkelman G, Jónsson $H$. Improved tangent estimate in the nudged elastic band method for finding minimum energy paths and saddle points. J Chem Phys, 2000, 113: 9978-9985

71 Henkelman G, Uberuaga BP, Jónsson H. A climbing image nudged elastic band method for finding saddle points and minimum energy paths. J Chem Phys, 2000, 113: 9901-9904

72 Henkelman G, Jónsson H. A dimer method for finding saddle points on high dimensional potential surfaces using only first derivatives. J Chem Phys, 1999, 111: 7010-7022

73 Kästner J, Sherwood P. Superlinearly converging dimer method for transition state search. J Chem Phys, 2008, 128: 014106

$74 \mathrm{Su} \mathrm{J}, \mathrm{Hu} \mathrm{S}$, Huang W, et al. On the oxidation states of metal elements in $\mathrm{MO}_{3}{ }^{-}(\mathrm{M}=\mathrm{V}, \mathrm{Nb}, \mathrm{Ta}, \mathrm{Db}, \mathrm{Pr}, \mathrm{Gd}, \mathrm{Pa})$ anions. Sci China Chem, 2016, 59: 442-451

75 Ma XL, Liu JC, Xiao H, et al. Surface single-cluster catalyst for $\mathrm{N}_{2-}$ to- $\mathrm{NH}_{3}$ thermal conversion. J Am Chem Soc, 2018, 140: 46-49

76 Liu JC, Ma XL, Li Y, et al. Heterogeneous $\mathrm{Fe}_{3}$ single-cluster catalyst for ammonia synthesis via an associative mechanism. Nat Commun, 2018, 9: 1610 tional Natural Science Foundation of China (21590792, 91426302 and 21433005) to Li J. The support from Guangdong Provincial Key Laboratory of Catalysis (2020B121201002) is also acknowledged. The calculations were performed using supercomputers at Tsinghua National Laboratory for Information Science and Technology. Yu X thanks for the Special Funding for Transformation of Scientific and Technological Achievements in Qinghai Province (2018-GX-101), and the Natural Science Basic Research Program of Shaanxi Province (2019JM-226).

Author contributions Li J designed the research. Talib SH and Yu X performed the calculations. Talib SH, Yu X, Yu Q, Baskaran S, and Li J interpreted the data. Talib SH, Yu X, Yu Q and Li J co-wrote and revised the manuscript.

Conflict of interest The authors declare no conflict of interest.

Supplementary information Experimental details and supporting data are available in the online version of the paper.

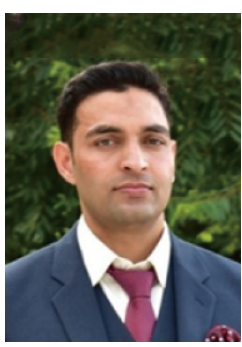

Shamraiz Hussain Talib is currently a $\mathrm{PhD}$ candidate at the Department of Chemistry and Key Laboratory of Organic Optoelectronics \& Molecular Engineering, Tsinghua University, under the supervision of Prof. Jun Li. He received his M. Phil degree (majored in chemistry) from the Department of Chemistry, Mohi-Ud-Din Islamic University, AJ\&K, Pakistan in 2016. His $\mathrm{PhD}$ research focuses on the theoretical investigations on heterogeneous single-atom catalysts.

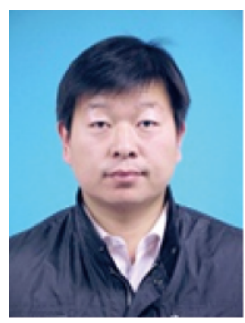

Xiaohu Yu received his $\mathrm{PhD}$ degree from the Institute of Coal Chemistry, Chinese Academy of Sciences in 2013. He did postdoctoral research at Moscow Institute of Physics and Technology from 2013 to 2015. He worked as a visiting scholar in Prof. Jun Li's group at Tsinghua University from 2019 to 2020 . He is now an associative professor at Shaanxi University of Technology. His research interests focus on theoretical inorganic chemistry and computational cataysis science.

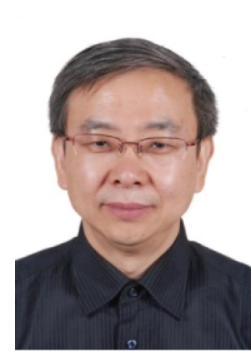

Jun Li received his $\mathrm{PhD}$ degree from Fujian Institute of Research on the Structure of Matter, Chinese Academy of Sciences in 1992. He did postdoctoral research at the University of Siegen and Ohio State University from 1994 to 1997 . He worked as a research scientist at Ohio State University and senior research scientist at the Pacific Northwest National Laboratory from 1997 to 2009 . He is now a full professor at Tsinghua University. His research involves theoretical chemistry, heavy-element chemistry, and computational catalysis science.

Acknowledgements This work was financially supported by the Na- 


\section{磷铇酸负载的非贵金属单原子催化剂: 乙烯环氧 化的理论研究}

Shamraiz Hussain Talib ${ }^{1}$, 于小虎 ${ }^{2^{*}}$, 于琦 ${ }^{3}$, Sambath Baskaran ${ }^{4}$, 李隽 ${ }^{1,4^{*}}$

摘要 基于第一性原理, 本文系统研究了过渡金属单原子(铁, 钴, 镍, 钓, 铑, 钯, 锇, 铱, 铂)负载在磷铇酸 (PTA) 催化剂上的几何和电 子结构, 并进一步研究了乙烯环氧化在铁单原子催化剂上的可能 反应机理. 我们发现PTA最可能结合过渡金属单原子的位置是四 配位中空位. 乙烯环氧化催化活性的理论计算表明, 非贵金属 $\mathrm{Fe}_{1}$ PTA具有可观的吸附能, 这是引发此催化循环的关键物理量. 我们 进一步进行了铁单原子和PTA结合的成键分析, 发现电荷从铁单原 子转移到PTA团簇, 并且强烈的 $\mathrm{Fe}-\mathrm{O}$ 共价金属-载体相互作用 (CMSI) 是其高稳定性的基础. 在催化剂 $\mathrm{Fe}_{1}-\mathrm{PTA}$ 上可能的乙烯环氧 化催化机理共包括三步: 1) 氧气分子通过电荷转移吸附在 $\mathrm{Fe}_{1}-\mathrm{PTA}$ 上; 2) 第一个乙烯分子攻击吸附在 $\mathrm{Fe}_{1}-\mathrm{PTA}$ 上的氧气分子, 随后形 成 $\mathrm{C}_{2} \mathrm{H}_{4} \mathrm{O}$;3) 表面吸附的氧原子和第二个乙烯分子生成 $\mathrm{C}_{2} \mathrm{H}_{4} \mathrm{O}$, 完 成催化循环. 本研究发现, $\mathrm{Fe}_{1}$-PTA对于乙烯环氧化主要通过EleyRideal 机理进行. 本工作为发展高效多相非贵金属单原子乙烯环氧 化催化剂提供了理论依据. 